\title{
Queuing system in E- Commerce
}

\section{S. Merlin, S. Maragathasundari, D.Senthilkumar, K.S. Dhanalakshmi}

\begin{abstract}
This paper explores an investigation on Queuing framework in E-trade. Online business (electronic trade) is the acquiring and selling of product and adventures, or the transmitting of benefits or data, over an electronic system, basically the web. It is the trading of things or administrations using PC systems like Internet or online casual networks. Here the Business is led utilizing PCs, phones, fax machines, standardized tag per users, Visas, ATM or other electronic apparatuses without the trading of paper-based records or physically moving to a strip mall. It incorporates exercises, for instance, acquirement, request passage, trade handling, online installment, verification, stock control, request satisfaction, shipment, and client support. In the Queuing arrangement of $E$ trade, the clients touches base in Batch with Reneging happens at the set-up time organize and Optional second stage where breakdown happens just as fix procedure will be done. Moreover, we accept that the clients may renege amid the Initial stage because of eagerness (Slow server) or Non-Satisfaction in acquiring the items from the specific site. At the season of Repair process, Strictly Non-acceptability of the clients is executed. The model is well analyzed and solved by supplementary variable method .The system performance measures are derived. Numerical analysis and graphical representation of the model clearly justifies the model to a fullest satisfaction.
\end{abstract}

Keywords: Set up time stage, optional second stage of service, Restricted admissibility

\section{INTRODUCTION}

Server suppliers that help web based business applications as an administration for various internet business Web destinations generally utilizes a layered server design. Web based business site proprietors on one side are thinking about how to pull in more clients and how to make the visitors feel verified when wearing down the webpage, while on the opposite side how the end clients should rate an internet business site and what they ought to do to ensure themselves as one among the online system. Security is a standout amongst the most imperative factors that confine clients and affiliations connecting with internet business and web based business right now tending to step by step for the security issues on their inside networks. As a substantial part of the clients those are using web based shopping some are

Revised Manuscript Received on December 15, 2019.

S. Merlin, Department of Mathematics, Kalasalingam Academy of Research and Education, Krishnankovil-626126, Tamilnadu. Email: merlinmcc59@gmail.com

S. Maragathasundari*, Department of Mathematics,Kalasalingam Academy of Research and Education, Krishnankovil-626126, Tamilnadu. Email: maragatham01@gmail.com

D. Senthilkumar, Department of Mathmematics, Velammal Institiute of Technology,Chennai,Tamilnadu,Email:senthil.d18@gmail.com

K.S. Dhanalakshmi, Department of Electronics and Communication Engineering, Kalasalingam Academy of Research and Education, Krishnankovil-626126, Tamilnadu. Email: k.s.dhanalakshmi@klu.ac.in
* Correspondence Author

proficient, and others are unskilled, along these lines teaching the buyer on security issues is still in the soonest organizes arrange.

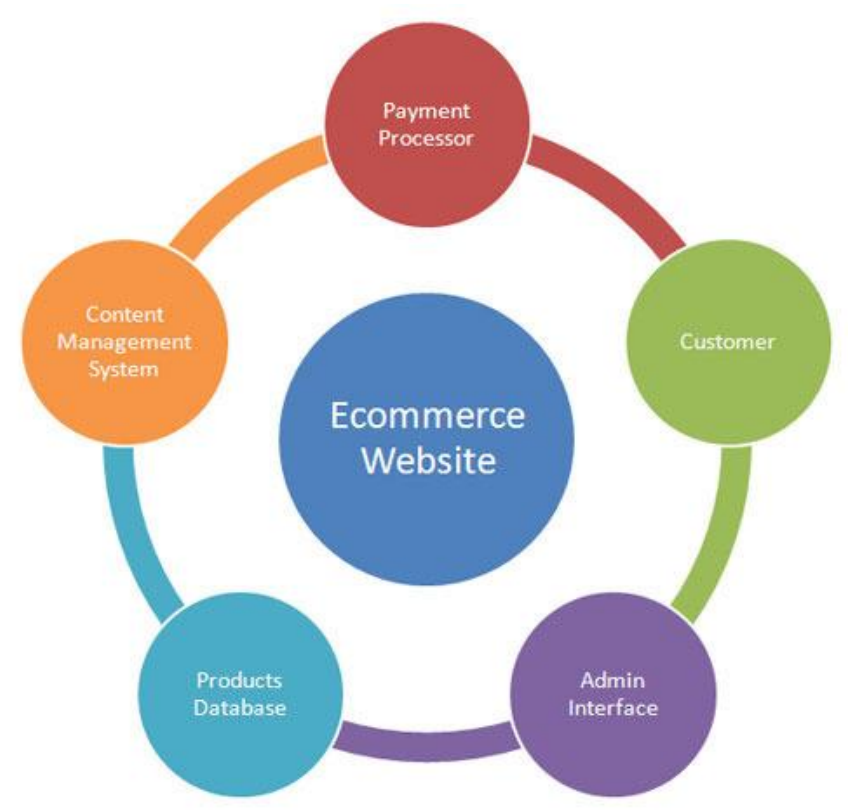

Fig. 1 Ecommerce website

\section{A. Performance requirements}

We assume the following to describe the queuing model of our study.

- Necessary first stage - Batch landing - Arrival of Online Customers (E-Com Site Visitors): Customers are accepted to touch base in groups as indicated by Poisson process and a solitary server gives administration to the clients.

Consider two sorts of client's Arrival procedure:

1) Occasional Buyers : Composed of clients who utilize the Web store to discover out about existing items, for example, new books or best fares and agendas for movement, however end up not purchasing, most of the time, at the Web store.

2) Heavy purchasers: Composed of clients who have a higher probability of purchasing in the event that they see an item that intrigues them at a reasonable cost.

- Set up time Stage - Elicitation: Customers regularly experiencing difficulty choosing what they need and afterward correspondence or following up on their choices. That makes issues for any organization meaning to serve those clients. 
- There are circumstances in which clients plainly articulate their necessities. All the more ordinarily, be that as it may, clients are uncertain. They are effectively overpowered by an excessive number of choices on a page.

- Reneging: The Web Server served the clients one by one on a first come - first served premise. Clients may renege amid server breakdown or amid server excursion because of fretfulness.

- Discretionary second stage - Online Payment Stage Hacking (Cyber Crime) Reason for breakdown in installment of online purchasers: If the client needs to purchase the items they need to add the items to their truck and need to pay for their choices. It is a basic to have an approved administration and specialized prerequisite for any proficient and viable Payment trade exercises over the web. Quick advancement in portable figuring and correspondence advances has encouraged pervasiveness of web based business. The key obstacle being developed of web based business is digital distortion and wholesale fraud. Programmers are individuals who complete the cybercrime. Henceforth, poor security on internet business prompts breakdown of clients or Server (amid installment).

- Fix Process - Authentication of Payer/Payment (Restricted Admissibility): The installment entryways and banks giving setting aside extra cash and budgetary administration ought to in like manner be totally digital secure. In the event that any issues arised in installment amid buy of the item, at that point Issues might be Raise through the worry clients or by the bank gateway for verifying the clients' validation just as cash. Henceforth the fix procedure deals with such installment related issues of their clients, and validates the installment amid their buy of items from their Web server. Amid this Period, no new clients might be urged to enter the procedure/line. In this way restricted suitability will be pursued amid such fix process. (Just validated purchasers will go into this procedure) No new clients will be permitted here.

\section{B. Queuing issue in E- commerce}

In this issue, clients land in groups pursues a Poisson circulation. Here the administration is given in two phases to all the arriving clients based on FCFS discipline. The principal phase of administration is mandatory and the second phase of administration is discretionary. In some genuine circumstances, the server regularly needs a startup time before it really begins serving another client. This arbitrary setup time is generally named as SET so as to set the framework into an employable mode before the second phase of administration starts. Over the span of time, the clients because of restlessness, leave the framework subsequent to joining the line Also, because of different reasons, the framework may expose to separate. When the framework separates, the fix procedure will be begun promptly immediately. As the server goes for a fix procedure, the line for administration will be stretched. It prompts clog in the framework. So to limit the clog, the idea of confined tolerability is presented amid the season of the fix procedure

The above Queuing issue in E-trade is illuminated by the utilization of the valuable variable technique. Every one of the parameters like administration time, setup time and Repair process are given the strengthening factors in this issue. The issue is dissected by birth and the end procedure by creating capacity and beneficial strategy approach. "Reference [1] contemplated the exhibition examination of a group entry line with two phases of administration Bernoulli plan excursion expanded get-away and administration intrusion". "Reference [2] investigated the cluster landing Poisson line with summed up excursion". Versatile adhoc systems issue a queuing approach was very much investigated by [3]. "Reference [15] arranged and sorted out the aggregated information about portable shopping as uncovered in the present writing with respect to retail". "Reference [20] inspected the presentation demonstrating which turned out to be progressively significant in the structure, designing and improvement of data innovation frameworks and applications". "Reference [4] suggested that basic foundation like power and media transmission ought to be given abnormal state of dependability to guarantee the utilization of e-banking in Nigeria". "Reference [7] broke down an examination on A M[x]/G/1 Queue with Bernoulli timetable" and general fix times as [11] determined the presentation proportions of lining issue with Bernoulli excursion plan under limited tolerability approach. "Reference [12] considered a mass landing lining model of three phases of administration with various get-away arrangements", administration intrusion and deferral time. "Reference [13] examined a lining arrangement of general administration Distribution with a foundation time and second optional administration". "Reference [14] satisfactorily contemplated the Web Hosting Queuing". "Reference [16] exhibited the discoveries of a contextual investigation on the improvement of radio recurrence recognizable proof (RFID) model framework that is coordinated with portable business in a holder stop". "Reference [17] analyzed the commitment towards the advancement of a hypothetical comprehension of trust in E-commerce". "Reference [8] chipped away at Batch landing Queue with backup server amid general excursion time and general fix time". "Reference [10] made a broad investigation on a solitary server line with discretionary stage type server get-aways dependent on comprehensive deterministic administration". "Reference [5] analyzed the components of web administration quality dependent on e-client's desires and recognitions". "Reference [6] made the pertinence of significant worth measurements for web based shopping and the connection between esteem measurements, inclination towards the Internet retailer and aims.

\section{Mathematical description of the Queuing issue in E-Commerce}

$E_{n}^{(c)}(x)$-This represents the probability of $\mathrm{n}$ clients in the framework incorporating one client in mandatory stage 1 administration.

$S_{n}^{(t)}(x)$ - This represents the set up time probability before getting into the second stage of optional service.

$E_{n}^{(p)}(x)$ - Probability of second stage of optional service in which there are $\mathrm{n}$ number of customers in the system. 
$K_{n}(x)$ - Probability that there are n customers in the queue and server is on repair process.

All the above parameters follow a general distribution Let. $\epsilon_{c}(x) \mathrm{Be}$ the conditional probability of stage 1 compulsory service with distribution function $s^{*}(\mathrm{x})$ and density function $s^{c}(x)$ and it is given by

$$
\epsilon_{c}(x)=\frac{s^{c}(x)}{1-s^{*}(\mathrm{x})} \text { and } s^{c}(\mathrm{x})=\epsilon_{c}(x) \exp \left[-\int_{0}^{x} \epsilon_{c}(v) d v\right]
$$

Likewise, for the various parameters, we have

$$
\begin{aligned}
& \epsilon_{t}(x)=\frac{s^{t}(x)}{1-s_{1}^{*}(x)} \text { and } s^{t}(\mathrm{x})=\epsilon_{t}(x) \exp \left[-\int_{0}^{x} \epsilon_{t}(v) d v\right] \\
& \epsilon_{p}(x)=\frac{s^{p}(x)}{1-2(x)} \text { and } s^{p}(\mathrm{x})=\epsilon_{p}(x) \exp \left[-\int_{0}^{x} \epsilon_{p}(v) d v\right] \\
& \epsilon_{l}(x)=\frac{s^{k}(x)}{1-s_{3}^{*}(x)} \text { and } s^{k}(\mathrm{x})=\epsilon_{k}(x) \exp \left[-\int_{0}^{x} \epsilon_{k}(v) d v\right]
\end{aligned}
$$

During the optional stage of service, break down occurs. Arrival of break down follows a Poisson stream.

During the time of set up stage, due to impatience the customers leave the system after joining the queue. This concept is defined to be Reneging. Reneging is assumed to follow exponential distribution with parameter $\xi$.

To avoid the congestion in the system, the concept of restricted admissibility is introduced at the time of repair process .Regarding this, the parameter $\beta$ is considered in this model.

\section{HELPFUL HINTS}

$\frac{d}{d x} E_{n}^{(c)}(x)+\left(\lambda+\epsilon_{c}(x)\right) E_{n}^{(c)}(x)=\lambda \sum_{i=1}^{n} a_{i} E_{n-i}^{(c)}(x)$.

$\frac{d}{d x} E_{0}^{(c)}(x)+\left(\lambda+\epsilon_{c}(x)\right) E_{0}^{(c)}(x)=0$.

$\frac{d}{d x} S_{n}^{(t)}(x)+\left(\lambda+\epsilon_{t}(x)+\xi\right) S_{n}^{(t)}(x)=\lambda \sum_{i=1}^{n} a_{i} S_{n-i}^{(t)}(x)+$ $\xi S_{n+1}^{(t)}(x)$

(3)

$\frac{d}{d x} S_{o}^{(t)}(x)+\left(\lambda+\epsilon_{t}(x)+\xi\right) S_{o}^{(t)}(x)=0$

$\frac{d}{d x} E_{n}^{(p)}(x)+\left(\lambda+\epsilon_{p}(x)+\eta\right) E_{n}^{(p)}(x)=\lambda \sum_{i=1}^{n} a_{i} E_{n-i}^{(p)}(x)$.

$\frac{d}{d x} E_{0}^{(p)}(x)+\left(\lambda+\epsilon_{p}(x)+\eta\right) E_{0}^{(p)}(x)=0$.

(6)

$\frac{d}{d x} K_{n}(x)+\left(\lambda+\epsilon_{k}(x)\right) K_{n}(x)=\lambda \beta \sum_{i=1}^{n} a_{j} k_{n-i}(x)+$

$\lambda(1-\beta) K_{n}(x)$

(7)

$\frac{d}{d x} K_{0}(x)+\left(\lambda+\epsilon_{k}(x)\right) K_{0}(x)=\lambda(1-\beta) K_{0}(x)$.

$\lambda Q=\int_{0}^{\infty} K_{0}(x)+\left(\lambda+\epsilon_{k}(x)\right)+\int_{0}^{\infty} E_{0}^{p}(x) \epsilon_{p}(x) d x$.
The following boundary conditions are used to solve the above equations.

$E_{n}^{(c)}(0)=\int_{0}^{\infty} E_{n+1}^{(p)}(x) \epsilon_{p}(x) d x+\int_{0}^{\infty} K_{n+1}(x) \epsilon_{k}(x) d x+$ $p 0 \infty E n-1(c) x \in c x d x+$

$\lambda A n+1 Q$

(10)

$S_{n}^{(t)}(0)=k \int_{0}^{\infty} E_{n}^{(c)}(x) \epsilon_{c}(x) d x$

$E_{n}^{(p)}(0)=\int_{0}^{\infty} S_{n}^{(t)}(x) \epsilon_{t}(x) d x$

$K_{n}(0)=\int_{0}^{\infty} E_{n}^{p}(x) d x$.

\section{DISTRIBUTION FUNCTION OF THE QUEUE LENGTH}

\section{Solving of (1) to (8)}

Multiply (1) by $z^{n}$ and sum over $n$ from 1 to $\infty$ and add it to (2) resulting in the following equation

$$
\begin{aligned}
& \frac{d}{d x} E^{(c)}(x, z)+\left(\lambda-\lambda A(z)+\epsilon_{c}(x)\right) E^{(c)}(x, z)=0 \\
& \frac{d}{d x} S^{(t)}(x, z)+\left(\lambda-\lambda A(z)+\xi+\frac{\xi}{2}+\epsilon_{t}(x)\right) S^{(t)}(x, z)=0
\end{aligned}
$$

$$
\begin{aligned}
\frac{d}{d x} E^{p}(x, z)+\left(\lambda-\lambda A(z)+\epsilon_{p}(x)+\eta\right) E^{p}(x, z)=0 & \\
\frac{d}{d x} K(x, z)+\left(\lambda \beta-\lambda \beta A(z)+\epsilon_{k}(x)\right) K(x, z)=0 & \\
z E_{n}^{(c)}(0, z)=\int_{0}^{\infty} & E^{p}(x, z) \epsilon_{p}(x) d x \\
& +\int_{0}^{\infty} K_{n+1}(x, z) \epsilon_{k}(x) d x \\
& -\int_{0}^{\infty} E_{0}^{(p)}(x) \epsilon_{p}(x) d x \\
& -\int_{0}^{\infty} K_{0}(x, z) \epsilon_{k}(x) d x+\lambda A(z) Q
\end{aligned}
$$

Hence using (9) in the above we get,

$$
\begin{aligned}
& E^{(c)}(0, z)=\int_{0}^{\infty} E^{p}(x, z) \epsilon_{p}(x) d x+\int_{0}^{\infty} K(x, z) \epsilon_{k}((x)) d x+ \\
& \lambda Q(A z-1) \\
& (18) \\
& S^{t}(0, z)=k \int_{0}^{\infty} E^{c}(x, z) \epsilon_{c}(x) d x \\
& E^{p}(0, z)=\int_{0}^{\infty} S^{t}(x, z) \epsilon_{t}(x) d x
\end{aligned}
$$


Now integrating (14) from 0 to $x$, it gives

$E^{(c)}(x, z)=E^{(c)}(0, z) e^{-(\lambda-\lambda A(z))-\int_{0}^{x} \epsilon_{c}(t) d t}$

Integrating the above by parts,

$E^{(c)}(z)=E^{(c)}(0, z)\left(\frac{1-s^{*}(w)}{w}\right), w=\lambda-\lambda A(z)$.

Where $s^{*}(w)=\int_{0}^{\infty} e^{(\lambda-\lambda c(z)) x} d s(x)$ is the Laplace Stieltje's transform of the service time.

Again multiplying (22) both sides by $\epsilon_{c}(x)$ and integrating, we get

$\int_{0}^{\infty} E^{(c)}(x, z) \epsilon_{c}(x) d x=E^{(c)}(0, z) s^{*}(w)$.

Using (24) in (19), we get

$S^{t}(0, z)=k E^{(c)}(x, z) S^{*}(w)$

Similarly,

$$
\begin{aligned}
& S^{t}(z)=S^{t}(0, z)\left(\frac{1-s_{1}^{*}(b)}{b}\right), \text { where } b=\lambda-\lambda A(z)+\xi-\frac{\xi}{z} \\
& =k E^{(c)}(x, z) s^{*}(w)\left(\frac{1-s_{1}^{*}(b)}{b}\right) .
\end{aligned}
$$

$\int_{0}^{\infty} S^{t}(x, z) \epsilon_{t}(x) d x=k E^{(c)}(0, z) s^{*}(w) s_{1}^{*}(b)$.

Also, $E^{p}(z)=E^{p}(0, z)\left(\frac{1-s_{2}^{*}(c)}{c}\right)$, where $c=\lambda-\lambda A(z)+\beta$

$=k E^{(c)}(x, z) s^{*}(w) s_{1}^{*}(b)\left(\frac{1-s_{2}^{*}(c)}{c}\right)$

$\int_{0}^{\infty} E^{p}(x, z) \epsilon_{p}(x) d x=E^{p}(0, z) s_{2}^{*}(c)$

$=k E^{(c)}(0, z) s^{*}(w) s_{1}^{*}(b) s_{2}^{*}(c)$.

$k(z)=k(0, z)\left(\frac{1-s_{3}^{*}(d)}{d}\right)$

$=\eta z E^{p}(0, z)\left(\frac{1-s_{2}^{*}(c)}{c}\right)\left(\frac{1-s_{3}^{*}(d)}{d}\right)$

$=\eta z k E^{(c)}(0, z) s^{*}(w) s_{1}^{*}(b)\left(\frac{1-s_{2}^{*}(c)}{c}\right)\left(\frac{1-s_{3}^{*}(d)}{d}\right)$.

$\int_{0}^{\infty} k(z) \epsilon_{k}(x) d x=$

$\eta z k E(c) 0, z s *(w) s 1 *(b) 1-s 2 *(c) \operatorname{cs} 3 *(d)$.

(30)

Substituting (28) and (30) in (18), we get

$E^{(c)}(0, z)=\frac{\lambda Q(A(z)-1)}{z-k s^{*}(w) s_{1}^{*}(b)\left[s_{2}^{*}(c)-\eta z\left(\frac{1-s_{2}^{*}(c)}{c}\right) s_{3}^{*}(d)\right]}$.

Using (31) in (23), (25), (27) and (29), we get

$E^{(c)}(z)=\frac{-\lambda Q\left(1-s^{*}(w)\right)}{z-k s^{*}(w) s_{1}^{*}(b)\left[s_{2}^{*}(c)-\eta z\left(\frac{1-s_{2}^{*}(c)}{c}\right) s_{3}^{*}(d)\right]}$
$=\frac{E^{(p)}(z)}{z-k s^{*}(w) s_{1}^{*}(b)\left[s_{2}^{*}(c)-\eta z\left(\frac{1-s_{2}^{*}(c)}{c}\right) s_{3}^{*}(d)\right]}\left(\frac{1-s_{2}^{*}(c)}{c}\right)$

$s^{t}(z)$

$=\frac{k \lambda Q(A(z)-1) s^{*}(w)}{z-k s^{*}(w) s_{1}^{*}(b)\left[s_{2}^{*}(c)-\eta z\left(\frac{1-s_{2}^{*}(c)}{c}\right) s_{3}^{*}(d)\right]}\left(\frac{1-s_{1}^{*}(b)}{b}\right)$

$=\frac{k(z)}{z-k s^{*}(w) s_{1}^{*}(b)\left[s_{2}^{*}(c)-\eta z\left(\frac{1-s_{2}^{*}(c)}{c}\right) s_{3}^{*}(d)\right]}\left(\frac{1-s_{2}^{*}(c)}{c}\right)$

\section{PROBABILITY GENERATING FUNCTION OF THE QUEUE SIZE, IDLE TIME, UTILIZATION FACTOR, MEAN LENGTH OF THE QUEUE}

Let $R(z)$ be the probability generating function of the Queue size. Hence

$R(z)=E^{(c)}(z)+E^{(p)}(z)+s^{t}(z)+k(z)$

$R(z)=\frac{\lambda Q\left[-1+\left[k(A(z)-1) s^{*}(w)\right]\left\{\left(\frac{1-s_{1}^{*}(b)}{b}\right)+s_{1}^{*}(b)\left(\frac{1-s_{2}^{*}(c)}{c}\right)\left[1+\eta z s_{3}^{*}(d)\right]\right\}\right]}{z-k s^{*}(w) s_{1}^{*}(b)\left[s_{2}^{*}(c)-\eta z\left(\frac{1-s_{2}^{*}(c)}{c}\right) s_{3}^{*}(d)\right]}$

The idle time $Q$ is determined by using the normalization condition $R(1)+Q=1$

Using L'Hopital's rule, we get $\lim _{z \rightarrow 1} R(z)=\frac{N^{\prime}(1)}{D^{\prime}(1)}$

Also $Q=\frac{D^{\prime}(1)}{D^{\prime}(1)+N^{\prime}(1)}$ where,

$N^{\prime}(1)=\lambda k\left(\frac{1-s_{2}^{*}(\eta)}{\eta}\right)(1+\eta)$

$D^{\prime}(1)=1-k\left[\left[\lambda E(s)+(-\lambda+\xi) E\left(s_{1}\right)\right]\left[s_{2}^{*}(\eta)-\right.\right.$ $\eta 1-s 2 * \eta \eta+\lambda s 2 *^{\prime} \eta-\eta s 2 *^{\prime} \eta+1-s 2 * \eta \eta 1+E s 3 \lambda \beta$ (34)

From $Q$, the utilization factor $\rho$ can be determined.

Let $L_{q}$ be a probability to demonstrate the steady state typical number of customers in the line. By then

$L_{q}=\left.\frac{d}{d z} D_{q}^{*}(z)\right|_{z=1}=\left.\frac{d}{d z}\left\{\frac{N(Z)}{D(Z)}\right\}\right|_{Z=1}$

Where $N(Z)$ and $D(Z)$ are the numerator and denominator of (27).

Since $D_{q}^{*}(z)=\frac{0}{0}$ at $=1$, we utilize two fold separation and get

Published By:

Blue Eyes Intelligence Engineering

\& Sciences Publication 


$$
\begin{aligned}
& L_{q}=\lim _{z \rightarrow 1} \frac{d}{d z} D_{q}^{*}(z)=\frac{D^{\prime}(1) N^{\prime \prime}(1)-D^{\prime \prime}(1) N^{\prime}(1)}{2\left(D^{\prime}(1)\right)^{2}} . \\
& N^{\prime \prime}(1)=\lambda\left[2 k \lambda E(s)\left(\frac{1-s_{2}^{*}(\eta)}{\eta}\right)(1+\eta)+k\left\{E\left(s_{1}\right)-\right.\right. \\
& \left(E\left(s_{1}\right)(-\lambda+\xi)\left(\frac{1-s_{2}^{*}(\eta)}{\eta}\right) s_{2}^{*^{\prime}}(\eta)\right)[1+\eta]+ \\
& \left(E\left(s_{1}\right) \lambda\left(\frac{1-s_{2}^{*}(\eta)}{\eta}\right)-s_{2}^{*^{\prime}}(\eta)\right)\left[\eta+\eta E\left(s_{3}\right) \lambda \beta\right]+ \\
& \left.\left.\left(\frac{1-s_{2}^{*}(\eta)}{\eta}\right)\left[\eta E\left(s_{3}\right) \lambda \beta+\eta \lambda \beta E\left(s_{3}\right)+\eta(\lambda \beta)^{2} E\left(s_{3}^{2}\right)\right]\right\}\right] \text {. } \\
& \text { (36) } \\
& D^{\prime \prime}(1)=-k\left\{\left(\lambda^{2} E\left(s^{2}\right)-\lambda E\left(s_{1}\right) E(s)(-\lambda+\right.\right. \\
& \xi))\left(s_{2}^{*}(\eta)-\eta\left(\frac{1-s_{2}^{*}(\eta)}{\eta}\right)\right)+E(s) \lambda\left[-\lambda s_{2}^{*^{\prime}}(\eta)-\right. \\
& \left.\eta\left(s_{2}^{*^{\prime}}(\eta)+\left(\frac{1-s_{2}^{*}(\eta)}{\eta}\right)\left(1+E\left(s_{3}\right) \lambda \beta\right)\right)\right]+\left(s_{2}^{*}(\eta)-\right. \\
& \left.\eta\left(\frac{1-s_{2}^{*}(\eta)}{\eta}\right)\right)\left[-\lambda E(s) E\left(s_{1}\right)(-\lambda+\xi)+E\left(s_{1}^{2}\right)(-\lambda+\right. \\
& \left.\xi)^{2}+2 \xi E\left(s_{1}\right)\right]+\left[-\lambda s_{2}^{*^{\prime}}(\eta)-\eta\left(s_{2}^{*^{\prime}}(\eta)+\right.\right. \\
& \left.\left.\left(\frac{1-s_{2}^{*}(\eta)}{\eta}\right)\left(1+E\left(s_{3}\right) \lambda \beta\right)\right)\right][-\xi+\lambda] E\left(s_{1}\right)+ \\
& {\left[\lambda E(s)-E\left(s_{1}\right)(-\lambda+\xi)\right]\left[-\lambda s_{2}^{*^{\prime}}(\eta)-\eta\left[s_{2}^{*^{\prime}}(\eta)+\right.\right.} \\
& \left.\left.\left(\frac{1-s_{2}^{*}(\eta)}{\eta}\right)\left(1+E\left(s_{3}\right) \lambda \beta\right)\right]\right]+\lambda^{2} s_{2}^{*^{\prime \prime}}(\eta)-\eta\left[\lambda s_{2}^{*^{\prime}}(\eta)+\right. \\
& \lambda^{2} s_{2}^{*^{\prime \prime}}(\eta)+\lambda^{2} s_{2}^{*}(\eta) E\left(s_{3}\right)-s_{2}^{*^{\prime}}(\eta)+\left(\frac{1-s_{2}^{*}(\eta)}{\eta}\right) E\left(s_{3}\right)+ \\
& \lambda \beta E\left(s_{3}\right)\left(\frac{1-s_{2}^{*}(\eta)}{\eta}\right)-s_{2}^{*^{\prime}}(\eta) \lambda \beta E\left(s_{3}\right)+ \\
& \left.\left.\left(\frac{1-s_{2}^{*}(\eta)}{\eta}\right) E\left(s_{3}^{2}\right)(\lambda \beta)^{2}\right]\right\}
\end{aligned}
$$

Substituting (33), (34), (36) and (37) in (35), we obtain $L_{q}$ and all the other measures using Little's formula

$W_{q}=\frac{L_{q}}{\lambda}, W=\frac{L}{\lambda}, L=L_{q}+\rho$

\section{NUMERICAL JUSTIFICATION OF THE MODEL}

Assume that service time follows exponential distribution in particular and based on this condition, the numerical justification is elaborated below:

The values are collected accordingly: $\epsilon_{c}=2, \lambda=3, \epsilon_{t}=$ $4, \epsilon_{p}=3.5, \epsilon_{k}=2.5, k=0.5, \beta=0.5, \eta=3, \xi=$ $1 E(s)=\frac{1}{\epsilon_{c}}, E\left(s^{2}\right)=\frac{2}{\epsilon_{c}^{2}}, E\left(s_{1}\right)=\frac{1}{\epsilon_{t}}, E\left(s_{1}^{2}\right)=\frac{2}{\epsilon_{c}^{2}}, s_{2}^{*}(\eta)=$ $\frac{\epsilon_{p}}{\epsilon_{p}+\eta}, s_{2}^{*^{\prime}}(\eta)=\frac{-\epsilon_{p}}{\left(\epsilon_{p}+\eta\right)^{2}}, s_{2}^{*^{\prime \prime}}(\eta)=\frac{-2 \epsilon_{p}}{\left(\epsilon_{p}+\eta\right)^{3}}, E\left(s_{3}\right)=$ $\frac{1}{\epsilon_{k}}, E\left(s_{3}^{2}\right)=\frac{2}{\epsilon_{k}^{2}}$

Table- I: Tabulated values Regarding variation of $\xi=1,1.5,2,2.5,3$

\begin{tabular}{|c|c|c|c|c|c|}
\hline$Q$ & $\rho$ & $L_{q}$ & $L$ & $W_{q}$ & $W$ \\
\hline 0.5904 & 0.4096 & 1.9072 & 2.3168 & 0.6357 & 0.7723 \\
\hline 0.5895 & 0.4105 & 1.8649 & 2.2754 & 0.6216 & 0.7585 \\
\hline 0.5887 & 0.4113 & 1.8230 & 2.2343 & 0.6077 & 0.7448 \\
\hline 0.5878 & 0.4122 & 1.7813 & 2.1935 & 0.5938 & 0.7312 \\
\hline 0.5869 & 0.4131 & 1.7399 & 2.1530 & 0.5800 & 0.7177 \\
\hline
\end{tabular}

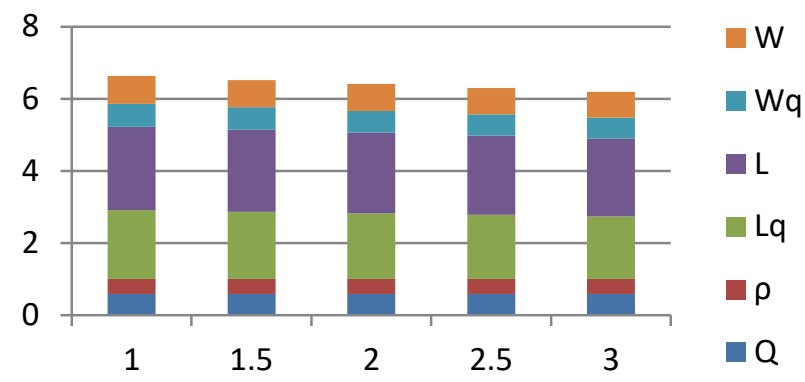

Fig 2. Variation of $\xi$.

Table- II: Tabulated values Regarding variation of

\begin{tabular}{|c|c|c|c|c|c|}
\hline$\eta$ & $\rho$ & $L_{q}$ & $L$ & $W_{q}$ & $W$ \\
\hline 0.5905 & 0.4095 & 1.3749 & 1.7844 & 0.4583 & 0.5948 \\
\hline 0.5895 & 0.4105 & 1.3035 & 1.7140 & 0.4345 & 0.5713 \\
\hline 0.5883 & 0.4117 & 1.1744 & 1.5861 & 0.3915 & 0.5287 \\
\hline 0.5879 & 0.4121 & 1.0281 & 1.4402 & 0.3427 & 0.4801 \\
\hline 0.5878 & 0.4122 & 0.9642 & 1.3764 & 0.3214 & 0.4588 \\
\hline
\end{tabular}

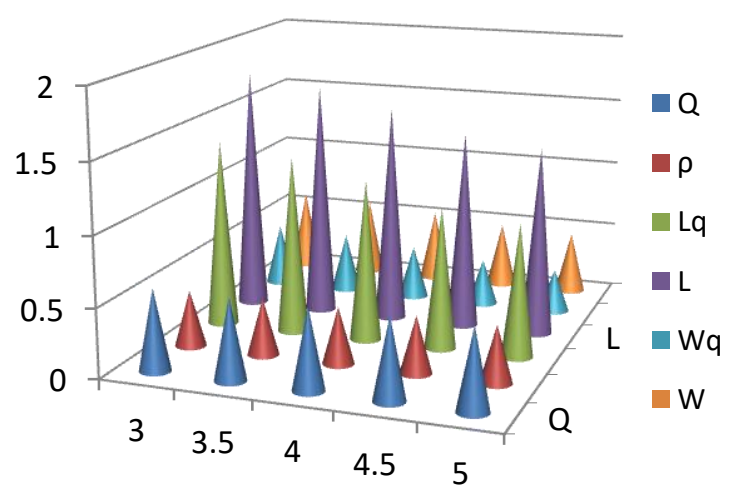

Fig3. Variation of $\eta$

Table- III: Tabulated values Regarding variation of

\begin{tabular}{|c|c|c|c|c|c|}
\hline \multicolumn{1}{c}{$\boldsymbol{\beta}=\mathbf{0 . 5}, \mathbf{0 . 6}, \mathbf{0 . 7}, \mathbf{0 . 8}, \mathbf{0 . 9}$} \\
\hline 0.5905 & $\rho$ & $L_{q}$ & $L$ & $W_{q}$ & $W$ \\
\hline 0.5955 & 0.4095 & 1.3751 & 1.7846 & 0.4584 & 0.5949 \\
\hline 0.6003 & 0.3997 & 1.4952 & 1.8997 & 0.4984 & 0.6332 \\
\hline 0.6051 & 0.3949 & 1.6216 & 2.0213 & 0.5405 & 0.6738 \\
\hline 0.6097 & 0.3903 & 1.9002 & 2.1529 & 0.5860 & 0.7176 \\
\hline
\end{tabular}




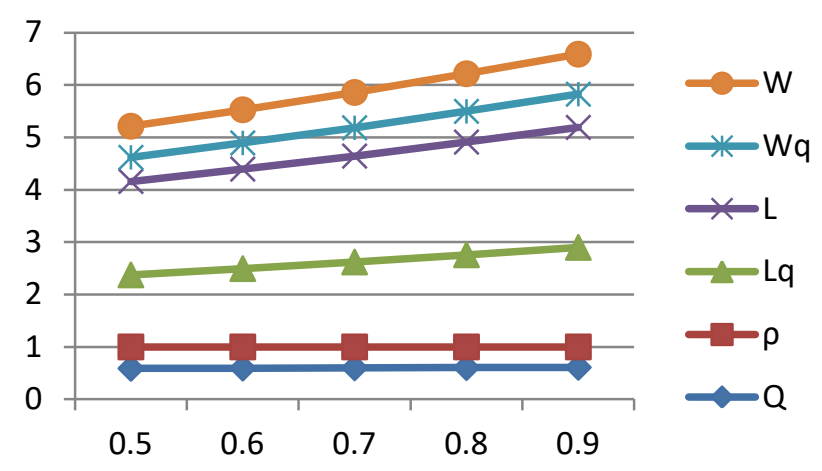

Fig4. Variation of $\beta$

\section{NUMERICAL ANALYSIS REPORT}

From Table 1, unmistakably as reneging builds, all the Queue execution measures get lesser. Table 2 gives the data that expanding the breakdown level should build the length of the line. Be that as it may, as the reneging happens at the same time, it diminishes the length of the line and furthermore the other line measures. Next from table3, we note that expanding the confined tolerability the normal length of the line, number of clients in the framework, holding up time of the clients in the framework just as the line gets intensified. Every one of the outcomes is true to form

\section{CONCLUSION}

In this work, we explored the clump entry lining framework with two phases of the administration in which the second stage is discretionary. Before getting into the second phase of administration, the idea of set up time is presented, this causes the framework to run easily. Amid the season of set up stage, clients leave the framework because of fretfulness. Also, amid the discretionary administration, administration interference happens and as soon the server gets intruded on it goes into a patch up procedure. All the arriving clients are not permitted to go into the framework amid the season of the fix procedure so as to keep away from the clog in the framework. The above lining issue is illuminated by the strengthening variable technique and line execution measures are determined. As a future work, the ideas of Balking, periods of administration and multi get-away approach can be actualized in this model.

\section{REFERENCES}

1. B. Balamurugan and S. Maragathasundari, "A study on the performance analysis of a batch arrival queue with two stages of service Bernoulli schedule vacation extended vacation and service interruption", International journal of computer applications, vol.124, no.12, 2015, pp.33-37.

2. A. Borthakur and G. Choudhury, "On a batch arrival Poisson queue with generalized vacation”, SankhyaSer.B, vol.59, no.3, 1997, pp.369-383.

3. Dhanalakshmi and S. Maragathasundari ,"Mobile adhoc networks problem- A queuing approach", International journal of communication networks and distributed systems, 2018, vol.21, No.4.

4. Elisha MensonAuta, "E-Banking in developing economy: Empirical evidence from Nigeria”, Journal of Applied Quantitative Methods, vol. 5, no. 2, 2010, pp. 212-222.

5. Godwin J. Udo, K. Kallo, Bagchi, Peeter J. Kirs, "An assessment of customers' e-service quality perception, satisfaction and intention", International Journal of Information Management, vol. 30, no. 6, 2010, pp. 481-492.

6. Jeffrey W. Overby, Eun-Julee, "The effects of utilitarian and hedonic online shopping value on consumer preference and intentions", Journal of Business Research, vol. 59, no. 10-11, 2006, pp. 1160-1166.
7. R.F. Khalaf, K. C. Madan, and C.A. Lucas, , "An $M^{[x]} / G / 1$ Queue with Bernoulli schedule, General vacation times, random breakdowns, general and general repair times", Applied mathematical sciences, Vol.5, No.1, 2011, pp. 35-51.

8. K. Karthikeyan and S. Maragathasundari (2015), "Batch arrival of two stages with standby server during general vacation time \& general repair time", International Journal of Mathematical archive, vol. 6, no.4, 2015, pp.43-48.

9. K.C. Madan and A.Z. Abu-Dayyeh, "On a single server queue with optional phase type server vacations based on exhaustive deterministic service and a single vacation policy", Applied Mathematics and Computation, vol.149, no.3, 2004, pp. 723-734.

10. K.C. Madan and G. Chodhury, "An $\mathrm{M}^{[\mathrm{x}]} / \mathrm{G} / 1$ queue with Bernoulli vacation schedule under restricted admissibility policy", Sankhaya, vol.66, 2004, pp. 172-193.

11. S. Maragathasundari, "A bulk arrival queuing model of three stages of service with different vacation policies, service interruption and delay time", American International Journal of Research in Science, Technology, Engineering \& Mathematics, vol.11, no.1, 2015, pp.52-56.

12. S. Maragathasundari, "An examination on queuing system of general service Distribution with an establishment time and second discretionary administration", International journal of applied and computational mathematics, 4: 97. https://doi.org/10.1007/s40819-018-0529-3 SPRINGER.

13. S. Maragathasundari and Miriam Cathy Joy , "Queuing model of optional type of services with service stoppage and revamp process in Web Hosting Queuing", International journal of knowledge management in Travel and hospitality, vol.1, no.2, 2018, pp.241-262.

14. Michael Grab, "Mobile shopping: a classification framework and literature review", International Journal of Retail and Distribution Management, vol. 43, no. 3, 2015, pp. 221-241.

15. E.W.T. Ngai, T.C.E. Cheng, S. Au, Kee-hung Lai, "Mobile commerce integrated with RFID technology in a container depot", Elsevier Decision Support Systems, vol. 43, no. 1, 2007, pp. 62-76.

16. Sandy C. Chen, Gurpreet S. Dhillon, "Interpreting dimensions of consumer trust in E-Commerce", Information technology and Management, vol. 4, no. 2-3, 2003, pp. 303-318.

17. S. Sowmiah and S. Maragathasundari, "A study on the analysis of performance measure of bulk input queue with $\mathrm{N}$ type of additional optional service, service interruption and deterministic vacation", Imperial Journal of Interdisciplinary Research, vol. .2, no.8, 2016, pp.1436-1444.

18. S. Vignesh and S. Maragathasundari," Analysis of a non-Markovian single server batch arrival queuing system of compulsory three stages of services with fourth optional stage service, service interruptions and deterministic server vacations "International journal of operational research, vol.34, no.1, 2019, pp.28-53.

19. Zhen Liu, Laura winter, Cathy H. Xia, Fanzhang, "Parameter inference of queuing models for IT systems using end-to-end measurements", Elsevier Performance Evaluation, vol.63, No. 1, 2006, pp. 36-60.

\section{AUTHORS PROFILE}

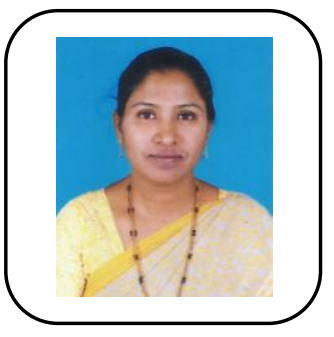

S.Merlin pursued her B.Sc. degree from University of Madras, in 1996. She got her M.Sc. degree in Madras Christian College, Tambaram in 1998 and her M.Phil. degree in Madras Christian College, Tambaram in 2000. She obtained her B.Ed. degree from Cresent college of Education, Tiruvannamalai in 2010. She is having $19 y$ rs. of teaching experience. At present she is working as an Assistant professor in department of Mathematics, Kalasalingam Academy of Research and Education, Anand Nagar, Tamilnadu. 


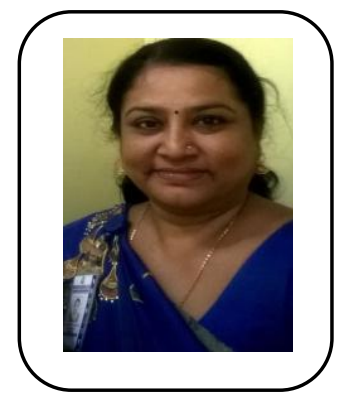

Dr. S. Maragatha Sundari acquired her B.Ed. degree from V.O.C Teachers College, Tuticorin in 1993. She got her M.Sc. in Mathematics from Manonmaniam Sundaranar University; Tirunelveli in 1995 and her M.Phil. degree from Madurai Kamaraj University, Madurai in 2003. She did her Ph.D. in Sathyabama University, Chennai, India. She has more than 17 years of instructing knowledge. She has distributed more than 50 inquire about papers in national and international journals. She has displayed and distributed papers at national and international conferences. She is right now filling in as an Associate Professor in the Department of Mathematics in Kalasalingam Academy of Research And Education, Anand Nagar, Tamilnadu, Krishnankovil-626126, India. In addition, she is doing her research guidance for five research scholars.

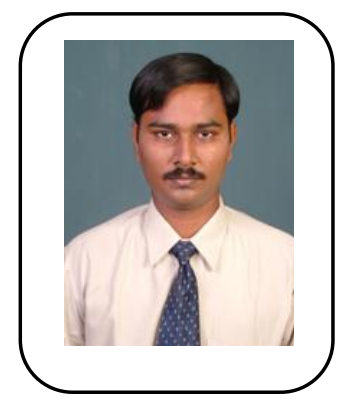

D.Senthilkumar is currently working as a Assistant Professor in the Department of Mathematics, Velammal Institute of Technology, Chennai from 2011.He holds his Bachelor of Science degree in Mathematics from RKM vivekananda college. He completed Master of Science and Master of philosophy degree with first class division. He has ten years of teaching experience in private engineering colleges and a life member of AICTE. He has published one journal.

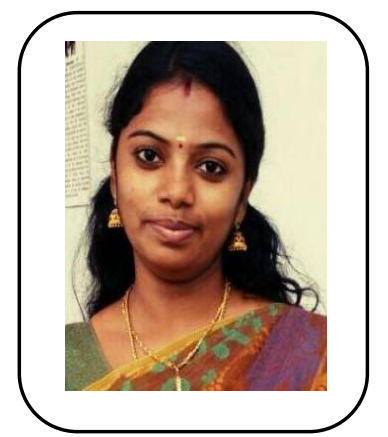

K.S. Dhanalakshmi graduated with her $\mathrm{BE}$ in Electronics and Communication Engineering from the Anna University, Chennai in 2007 and MTech. in Digital Communication and Network Engineering from the Kalasalingam University, Krishnankoil. Since 2010, she has been working as an Assistant Professor in the Department of Electronics and Communication Engineering, Kalasalingam University, Krishnankoil, Virudhunagar District, Tamil Nadu, India. She started her PhD research work in July 2013. She has attended several national/international conferences and has presented papers in conference. She has published three papers in an international journal. She is acting as a reviewer for Inderscience - International Journal of Reasoning-based Intelligent Systems (IJRIS), IEEE Communications Magazine and The Open Bioinformatics Journal. Her area of interest is wireless network security, satellite communication and signal processing. 